\title{
Components of physical fitness as prognostic factors for falls in elderly female exercise practitioners: a longitudinal study
}

\author{
Elementos da aptidão física como prognóstico de quedas em \\ idosas praticantes de exercício físico: um estudo longitudinal
}

\author{
Giovana Zarpellon Mazo ${ }^{[a]}\left[\mathbb{D}\right.$, Raquel Ester Lima ${ }^{[b]}\left[\mathbb{D}\right.$, Pedro Silvelo Franco ${ }^{[a]} \mathbb{D}$, Leonardo Hoffmann ${ }^{[a]}[\mathbb{D}$, \\ Enaiane Cristina Menezes ${ }^{[a]}[\mathbb{D} *$
}

[a] Universidade do Estado de Santa Catarina (UDESC), Florianópolis, SC, Brazil

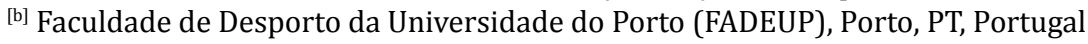

\begin{abstract}
Introduction: Physical exercise is used as a strategy for the prevention of falls because it improves the physical fitness of older adults. Objective: To determine which components of physical fitness are predictors of falls in elderly female exercise practitioners. Method: Longitudinal, descriptive, comparative study. The components of physical fitness (upper and lower limb strength and flexibility, agility, aerobic endurance, and hand grip strength) and the occurrence or not of falls in the last 12 months were analyzed in 80 older women practitioners of exercise from 2013 to 2016. Descriptive analysis, ROC curve attributing cut-off points, and binary logistic regression for the prediction of falls were used. Results: The mean age of the participants was 67.46 years $(\mathrm{SD}=7.65)$. Over the years, a significant difference between elderly fallers and non-fallers was observed for right hand grip strength (2013 and 2015), left hand grip strength (2014 and 2015), lower limb flexibility (2013, 2014 and 2015), agility (2015), and aerobic endurance (2015). In adjusted analysis, older women with poor lower limb flexibility in 2013 had a higher risk of falls in 2016
\end{abstract}

*GZM: PhD, e-mail: giovana.mazo@udesc.br

REL: Doctoral Student, e-mail: raquelesterlima@hotmail.com

PSF: Doctoral Student, e-mail: pedsilfra@hotmail.com

LH: MS, e-mail: leohoffmann1@hotmail.com

ECM: PhD, e-mail: enaianemenezes@gmail.com 
$(\mathrm{OR}=4.98$; 95\%CI 1.12 - 22.1). Older women with poor flexibility in 2015 also had a higher risk of falls $(\mathrm{OR}=6.08$; 95\%CI 1.06 - 34.67). Conclusion: Poor performance in the lower limb flexibility, right and left hand grip strength, agility and aerobic endurance tests was associated with falls and these components are predictors of future falls in elderly exercise practitioners.

Keywords: Elderly. Falls. Prognosis. Physical Fitness.

\section{Resumo}

Introdução: O exercício físico é utilizado como estratégia para prevenção de quedas, pois melhora a aptidão física dos idosos. Objetivo: verificar quais os elementos da aptidão física são preditores de quedas em idosas que praticaram exercício físico. Método: Estudo longitudinal descritivo comparativo. Analisou-se os elementos da aptidão física (força e flexibilidade de membros superiores e inferiores, agilidade, resistência aeróbia e força de preensão manual) e do relato de ocorrência ou não de quedas nos últimos 12 meses, de 80 idosas que praticaram exercícios físicos, no período de 2013 a 2016. Foi realizada análise descritiva, curva ROC atribuindo pontos de corte e regressão logística binária para predição de quedas. Resultados: A média de idade das idosas foi de 67,46 (dp=7,65). Com os anos, as variáveis que apresentaram diferença significativa entre as idosas caidoras e não caidoras foram a força de preensão manual direita (2013 e 2015), força de preensão manual esquerda (2014 e 2015), flexibilidade de membros inferiores (2013, 2014 e 2015), agilidade (2015) e resistência aeróbia (2015). Na análise ajustada, as idosas com flexibilidade de membros inferiores ruim em 2013 apresentaram mais chances de terem quedas em 2016 (OR=4,98; 1,12 - 22,1). Em 2015, as idosas com pior flexibilidade também apresentaram mais chances de terem quedas (OR=6,08; IC95\% 1,06 - 34,67). Conclusão: Piores desempenhos na flexibilidade de membros inferiores, força de preensão manual direita e esquerda, agilidade e resistência aeróbia associaram-se com quedas e são preditores de quedas futuras em idosas que praticaram exercícios físicos.

Palavras-chave: Idoso. Quedas. Prognóstico. Aptidão Física.

\section{Introduction}

The aging of the population is changing the approach to healthcare for the elderly [1]. In Brazil, the population has shown greater longevity, with an increase of the aging index from $19.8 \%$ in 2000 to $30.7 \%$ in 2010 [2]. This increase was also evident in 2016. According to data from the Ministry of Health, Brazil had the largest elderly population in the world in that year and estimates indicate that in 2030 the number of older adults will exceed that of children between 0 and 14 years of age [2].

The physiological changes that occur during aging can be accompanied by systemic dysfunctions that interfere with the functional independence of older adults [3]. The latter is fundamental for the execution of basic and instrumental activities of daily living since changes in functional capacities have implications for the prevention and treatment of degenerative diseases that increase with age [4].
The loss of functional capacity can increase the risk of falls and reduce the quality of life of older adults [4]. The main risk factors of falls in the elderly can be divided into intrinsic and extrinsic factors, which include advancing age, sex (female), neuromuscular deficit, chronic diseases, a history of falls, psychocognitive impairment, use of multiple medications, inadequate environment, and functional disability [5]. Falls are caused by the loss of postural balance due to the inability to recruit neural and musculoskeletal mechanisms necessary to maintain posture $[5,6]$. Muscle strengthening exercises are one factor that needs to be trained in older adults in order to reduce the risk of falls [7]. Physical exercise plays an important role in increasing muscle mass and strength $[8,9]$. Social activities and programs involving exercises contribute to the maintenance of this capacity and, consequently, of independence [6]. 
Some studies have analyzed the relationship between physical fitness and falls in older adults $[7,10$, 11]. Physical fitness is known to decrease with advancing age [12] and exercise is used as a strategy to prevent falls $[13,14]$. However, longitudinal follow-up studies of physical fitness components and respective reference values for the prediction of future falls in older women are still lacking. Therefore, the aim of this study was to determine which components of physical fitness are predictors of falls in elderly female exercise practitioners.

\section{Method}

This was a longitudinal, descriptive, comparative study that used data from the database of the Laboratory of Gerontology (LAGER), Center for Health and Sports Sciences (CEFID), State University of Santa Catarina (UDESC), comprising the period from 2013 to 2016. The use of the data was authorized by the coordinator of the laboratory. The study was approved by the Ethics Committee on Research Involving
Humans of UDESC (Ethical Clearance Certificate number 14957313.9.0000.0118 and Approval number $052406 / 2015$ ) according to Resolution 466/12 of the National Health Council.

The study that generated the database was started in 2013 and involved older women participating in a given exercise modality of the Extension Program Study Group for the Elderly (GETI) of CEFID/UDESC, such as water gymnastics, swimming, dancing, gymnastics, Pilates, walking, and weight training. The first four modalities were offered twice a week and the last two three times per week, with a duration of each session of $50 \mathrm{~min}$. The older women were followed up from 2013 to 2016.

The age, marital status, education level, self-reported disease, and body mass index (BMI) of the older women in 2013 were extracted from this database, as well as the results of each physical fitness test (exposure) performed and the occurrence or not of falls in the last 12 months (outcome) corresponding to the period from 2013 to 2016. Women who did not participate in the GETI activities or who were not evaluated in any of the years were excluded. Thus, 80 older women participated in the study as shown in Figure 1.

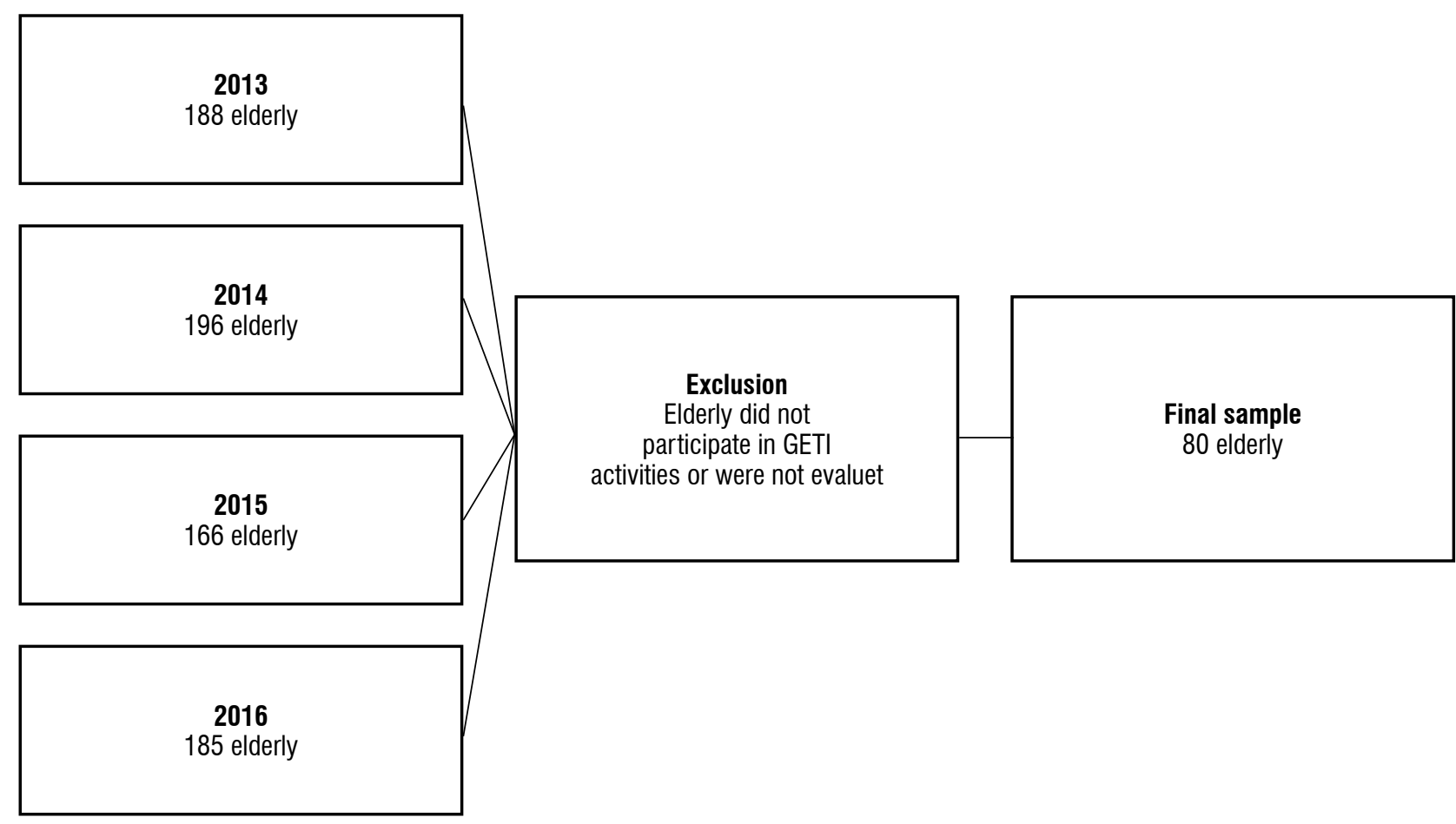

Figure 1- Flow diagram of the participants through the study. Note: GETI - Extension Program Study Group for the Elderly. Source: The authors. 
The fitness components were analyzed using seven physical tests. Six of them are part of the Senior Fitness Test (SFT) battery [15]: chair stand (lower limbs); forearm flexion (upper limbs); height/weight; sit and reach (lower limb flexibility); stand up from a chair, walk 2.44 $\mathrm{m}$ and sit down again (agility/dynamic balance); reach behind the back (upper limb flexibility), and 2 minutes of step (aerobic endurance) as an alternative to the 6-minute walk test because of time and space limitations. In addition, the right and left hand grip strength (kgf) of the participants was measured with a Saehan dynamometer (model SH5001) according to the recommendations of the American Society of Hand Therapists [16]. The tests were carried out in a circuit always by the same trained and calibrated evaluator to ensure reliability of the results.

Data treatment consisted of descriptive statistics, calculating measures of position and dispersion (numerical variables) or relativeand absolute frequencies (categorical variables). The Kolmogorov-Smirnov test was applied to verify normality of the data. The physical fitness components in 2013, 2014 and 2015 and the occurrence of falls (yes or no) in 2016 were compared between fallers and non-fallers by the independent t-test or Mann-Whitney U test depending on the distribution of the data.

In the case of physical fitness components that differed between elderly fallers and non-fallers, a cut-off point with sensitivity and specificity was attributed to predict falls in 2016 using ROC curves. Based on the cut-off points proposed by the ROC curve, the physical fitness components were classified (good or poor) and binary logistic regression was performed to determine the risk of falls in 2016 using the proposed cut-off.

\section{Results}

In 2013, the sample consisted of 80 women with a mean age of 67.46 years ( $\mathrm{SD}=7.65)$. Most women were married (50\%) and had elementary school (41.3\%) and excess body weight (83.7\%). The most reported diseases were arterial hypertension (37.5\%) and arthrosis (25\%). The prevalence of falls was $25 \%$ in $2014(\mathrm{n}=20), 17 \%$ in $2015(\mathrm{n}=14)$, and 15\% in 2016 ( $\mathrm{n}=12)$ (Table 1).
Table 1 - Characteristics of the participants in the study

\begin{tabular}{|c|c|c|}
\hline & $\mathbf{n}$ & $\%$ \\
\hline \multicolumn{3}{|l|}{ Marital status $(n=76)$} \\
\hline Single & 7 & 8.8 \\
\hline Married & 40 & 50.0 \\
\hline Divorced & 7 & 8.8 \\
\hline Widowed & 22 & 27.5 \\
\hline \multicolumn{3}{|c|}{ Education level ( $n=75)$} \\
\hline Elementary school & 31 & 41.3 \\
\hline High school & 24 & 32.0 \\
\hline Higher education & 20 & 26.7 \\
\hline \multicolumn{3}{|c|}{ Self-reported diseases $(n=78)$} \\
\hline Arterial hypertension & 30 & 37.5 \\
\hline Arthrosis & 20 & 25.0 \\
\hline Dyslipidemia & 13 & 16.3 \\
\hline Osteoporosis & 9 & 11.3 \\
\hline Diabetes mellitus & 6 & 7.5 \\
\hline \multicolumn{3}{|l|}{ BMI $(n=79)$} \\
\hline Normal & 13 & 16.3 \\
\hline Excess & 66 & 83.7 \\
\hline \multicolumn{3}{|l|}{$\begin{array}{l}\text { Prevalence of falls } \\
\text { (last } 12 \text { months) }\end{array}$} \\
\hline \multicolumn{3}{|l|}{$2014(n=74)$} \\
\hline Fallers & 20 & 25.0 \\
\hline Non-fallers & 54 & 67.5 \\
\hline \multicolumn{3}{|l|}{$2015(n=72)$} \\
\hline Fallers & 14 & 17.0 \\
\hline Non-fallers & 58 & 72.5 \\
\hline \multicolumn{3}{|l|}{$2016(n=73)$} \\
\hline Fallers & 12 & 15.0 \\
\hline Non-fallers & 61 & 76.3 \\
\hline
\end{tabular}


Table 2 shows the comparison of physical fitness components (2013-2015) between women who were fallers and non-fallers in 2016. Significant differences between fallers and non-fallers were observed for the following components: lower limb flexibility in 2013 ( $\mathrm{p}=0.008)$, $2014(\mathrm{p}=0.007)$ and $2015(\mathrm{p}=0.028)$, right hand grip strength in 2013 ( $\mathrm{p}=0.044)$ and $2015(\mathrm{p}=0.011)$, and left hand grip strength in $2014(\mathrm{p}=0.030)$ and 2015 ( $\mathrm{p}=0.044)$, as well as upper limb strength ( $\mathrm{p}=0.013)$, agility ( $\mathrm{p}=0.047)$, and aerobic endurance $(\mathrm{p}=0.032)$ in 2015.

Table 2 - Comparison of physical fitness components between elderly fallers and non-fallers in $2016(n=80)$

\begin{tabular}{|c|c|c|c|}
\hline Variable & $\begin{array}{c}\text { Fallers }(n=12) \\
\text { Mean (SD) }\end{array}$ & $\begin{array}{c}\text { Non-fallers }(n=61) \\
\text { Mean (SD) }\end{array}$ & $\mathrm{p}$-value \\
\hline \multicolumn{4}{|c|}{ Hand grip strength ${ }^{\mathrm{kgf}}$} \\
\hline \multicolumn{4}{|l|}{ Right } \\
\hline $2013 €$ & $18.99(3.67)$ & $21.62(4.32)$ & $0.044^{*}$ \\
\hline 2014\# & $21.00(4.81)$ & $23.95(4.81)$ & 0.056 \\
\hline $2015 \#$ & $18.75(5.82)$ & $22.85(4.81)$ & $0.011^{*}$ \\
\hline \multicolumn{4}{|l|}{ Left } \\
\hline $2013 €$ & $17.33(4.03)$ & $19.70(4.47)$ & 0.124 \\
\hline 2014\# & $18.67(3.68)$ & $21.70(4.44)$ & $0.030^{*}$ \\
\hline 2015\# & $18.00(4.11)$ & $20.92(4.58)$ & $0.044^{*}$ \\
\hline \multicolumn{4}{|c|}{ Lower limp strength ${ }^{\text {rep }}$} \\
\hline $2013 €$ & $13.00(2.70)$ & $14.32(3.18)$ & 0.180 \\
\hline $2014 €$ & $13.33(3.52)$ & $12.85(2.93)$ & 0.922 \\
\hline $2015 €$ & $12.75(2.80)$ & $14.42(2.88)$ & 0.098 \\
\hline \multicolumn{4}{|c|}{ Upper limb strengthrep } \\
\hline 2013\# & 14.33 (3.98) & $16.52(3.85)$ & 0.078 \\
\hline 2014\# & $15.58(2.81)$ & $15.10(3.56)$ & 0.658 \\
\hline 2015\# & $14.00(3.05)$ & $16.56(3.19)$ & $0.013^{*}$ \\
\hline \multicolumn{4}{|c|}{ Lower limb flexibilitycm } \\
\hline $2013 €$ & $-3.08(9.95)$ & $6.87(9.21)$ & $0.008^{*}$ \\
\hline $2014 €$ & $-4.75(8.13)$ & $2.18(7.71)$ & $0.007^{*}$ \\
\hline $2015 €$ & $-2.46(7.77)$ & $3.43(8.41)$ & $0.028 *$ \\
\hline \multicolumn{4}{|c|}{ Upper limb flexibilitycm } \\
\hline \multicolumn{4}{|c|}{ Right } \\
\hline 2013\# & $-9.45(9.25)$ & $-7.60(10.43)$ & 0.569 \\
\hline $2014 €$ & $-10.00(10.66)$ & $-9.53(12.72)$ & 0.783 \\
\hline $2015 €$ & $-10.13(12.46)$ & $-10.42(12.24)$ & 0.876 \\
\hline \multicolumn{4}{|c|}{$1102(0,30)$} \\
\hline 2013\# & $-12.28(9.33)$ & $-11.92(9.39)$ & 0.904 \\
\hline 2014\# & $-15.27(11.15)$ & $-12.85(10.67)$ & 0.478 \\
\hline 2015\# & $-12.63(13.90)$ & $-14.30(11.65)$ & 0.660 \\
\hline \multicolumn{4}{|l|}{ Agility } \\
\hline $2013 €$ & $7.11(1.35)$ & $6.35(1.28)$ & 0.068 \\
\hline $2014 €$ & $7.11(1.72)$ & $6.49(1.93)$ & 0.164 \\
\hline $2015 €$ & $6.47(1.92)$ & $5.72(1.82)$ & $0.047^{\star}$ \\
\hline \multicolumn{4}{|l|}{ Aerobic endurance ${ }^{\mathrm{m}}$} \\
\hline $2013 €$ & $545.64(38.20)$ & $508.75(67.28)$ & 0.196 \\
\hline $2014 €$ & $494.00(106.08)$ & $544.70(77.81)$ & 0.119 \\
\hline $2015 €$ & $482.09(85.25)$ & $527.59(59.81)$ & $0.032^{\star}$ \\
\hline
\end{tabular}

Note: $\mathrm{SD}=$ standard deviation; $\mathrm{kgf}=$ kilogram-force; $\mathrm{m}=$ meter; rep=repetition; $\mathrm{cm}=$ centimeter; $\mathrm{sec}=$ second. \# independent $t$-test; $€$ MannWhitney U test. * Significant difference at $p<0.05$. 
The area under the curve, cut-off point attributed, and its respective sensitivity (ability to detect fallers) and specificity (ability to detect non-fallers) are shown in Table 3. As can be seen, the cut-off points for right (19.9 kgf in 2013 and $18 \mathrm{kgf}$ in 2015) and left hand grip strength (21 kgf in 2014 and $20 \mathrm{kgf}$ in 2015) and lower limb flexibility ( $3 \mathrm{~cm}$ in $2013,1 \mathrm{~cm}$ in 2014, and $3 \mathrm{~cm}$ in 2015) were similar in the years analyzed. In addition, right hand grip strength (75.4\% in 2013 and $83.6 \%$ in 2015), agility (85.2\% in 2015), and aerobic endurance ( $83.6 \%$ in 2015) provided the best specificity. The best sensitivity was obtained for left hand grip strength (75 in 2014 and 2015), lower limb flexibility (75\% in $2013,91.7 \%$ in 2014 , and $83.3 \%$ in 2015), and upper limb strength (91.7\% in 2015).

Table 3 - Diagnostic accuracy of physical fitness components for predicting falls in 2016

\begin{tabular}{|c|c|c|c|c|c|}
\hline \multicolumn{6}{|l|}{$\begin{array}{l}\text { Hand grip } \\
\text { strength }^{\text {ggt }}\end{array}$} \\
\hline \multicolumn{6}{|l|}{ Right } \\
\hline 2013 & 19.9 & 0.683 & 58.3 & 75.4 & 0.017 \\
\hline 2015 & 18 & 0.695 & 50.0 & 83.6 & 0.009 \\
\hline \multicolumn{6}{|l|}{ Left } \\
\hline 2014 & 21 & 0.686 & 75.0 & 50.8 & 0.015 \\
\hline 2015 & 20 & 0.680 & 75.0 & 55.7 & 0.019 \\
\hline \multicolumn{6}{|l|}{ Lower limb } \\
\hline 2013 & 3 & 0.745 & 75.0 & 60.7 & $<0.001$ \\
\hline 2014 & 1 & 0.747 & 91.7 & 49.2 & $<0.001$ \\
\hline 2015 & 3 & 0.702 & 83.3 & 50.8 & 0.006 \\
\hline \multicolumn{6}{|l|}{$\begin{array}{l}\text { Upper limb } \\
\text { strength }^{\text {rep }}\end{array}$} \\
\hline 2015 & 16 & 0.720 & 91.7 & 55.7 & 0.002 \\
\hline \multicolumn{6}{|l|}{ Agilitysec } \\
\hline 2015 & 6.31 & 0.682 & 50.0 & 85.2 & 0.045 \\
\hline \multicolumn{6}{|c|}{ Aerobic enduran ${ }^{\mathrm{cem}}$} \\
\hline 2015 & 485 & 0.697 & 75.0 & 83.6 & 0.008 \\
\hline
\end{tabular}

Note: $\mathrm{kgf}=$ kilogram-force; $\mathrm{cm}=$ centimeter; rep=repetition; $\mathrm{sec}=$ second; $\mathrm{m}=$ =meter.

Adjusted analysis (Table 4) showed that older women with poor lower limb flexibility in 2013 $(\mathrm{OR}=4.98$; 95\% CI $1.12-22.1)$ and $2015(\mathrm{OR}=6.08$; $95 \%$ CI 1.06 - 34.67) had a higher risk of falls in
2016 when compared to women with good flexibility. The remaining fitness components were no longer associated with the outcome (falls in 2016) after adjusted analysis.

Table 4 - Descriptive, bivariate and adjusted analysis of falls in 2016 among elderly exercise practitioners from Florianópolis, $\mathrm{SC}(\mathrm{n}=80)$

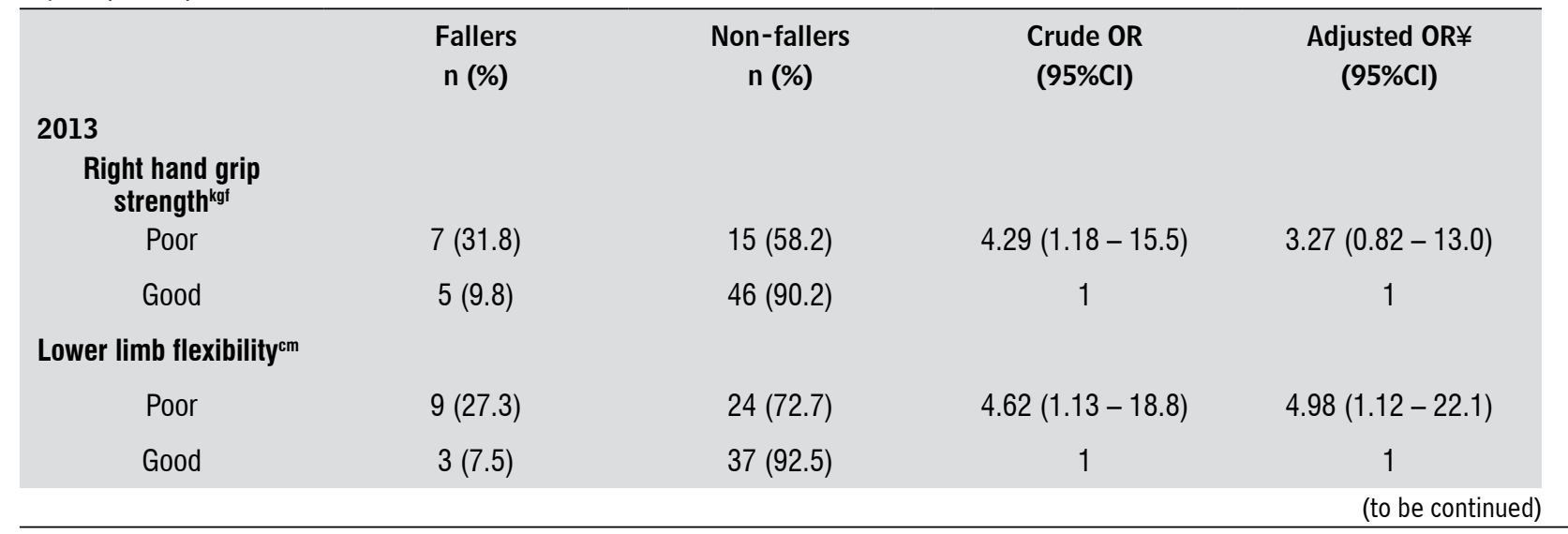


2014

Left hand grip

strength ${ }^{\mathrm{kgt}}$

$\begin{array}{lllcc}\text { Poor } & 8(22.2) & 28(77.8) & 2.35(0.64-8.6) & 2.29(0.56-9.23) \\ \text { Good } & 4(10.8) & 33(89.2) & 1 & 1\end{array}$

Lower limb flexibility

\begin{tabular}{|c|c|c|c|c|}
\hline Poor & $10(26.3)$ & $28(73.7)$ & $5.89(1.19-29.1)$ & $4.98(0.96-25.7)$ \\
\hline Good & $2(5.7)$ & $33(94.3)$ & 1 & 1 \\
\hline \multicolumn{5}{|l|}{2015} \\
\hline \multicolumn{5}{|l|}{$\begin{array}{l}\text { Left hand grip } \\
\text { strength }^{\text {kgt }}\end{array}$} \\
\hline Poor & $9(25.0)$ & $27(75.0)$ & $3.77(0.93-15.33)$ & $2.94(0.69-12.43)$ \\
\hline Good & $3(8.1)$ & $34(91.1)$ & 1 & 1 \\
\hline \multicolumn{5}{|l|}{$\begin{array}{l}\text { Right hand grip } \\
\text { strengthkgt }\end{array}$} \\
\hline Poor & $6(37.5)$ & $10(62.5)$ & $5.10(1.36-19.07)$ & $1.05(0.96-1.14)$ \\
\hline Good & $6(10.5)$ & $51(89.5)$ & 1 & 1 \\
\hline \multicolumn{5}{|c|}{ Lower limb flexibilitycm } \\
\hline Poor & $10(25.0)$ & $30(75.0)$ & $5.16(1.04-25.56)$ & $6.08(1.06-34.67)$ \\
\hline Good & $2(6.1)$ & $31(93.9)$ & 1 & 1 \\
\hline \multicolumn{5}{|l|}{ Agilitysec } \\
\hline Poor & $6(40.0)$ & $9(60.0)$ & $5.77(1.52-21.94)$ & $4.54(0.85-24.25)$ \\
\hline Good & $6(10.3)$ & $52(89.7)$ & 1 & 1 \\
\hline \multicolumn{5}{|c|}{ Aerobic endurance ${ }^{m}$} \\
\hline Poor & $9(47.4)$ & $10(52.6)$ & $15.30(3.51-66.6)$ & $14.79(2.84-77.04)$ \\
\hline Good & $3(5.6)$ & 51 (94.4) & 1 & 1 \\
\hline
\end{tabular}

Note: $\mathrm{OR}=$ odds ratio; $95 \% \mathrm{Cl}=95 \%$ confidence interval; $\mathrm{kgf}=$ kilogram-force; $\mathrm{cm}=$ centimeter. $¥$ Adjusted for self-reported disease, body mass index, and age.

\section{Discussion}

This study aimed to predict the occurrence of falls in older women who exercised in 2016 based on physical fitness components (hand grip strength, upper and lower limb strength, upper and lower limb flexibility, agility, and aerobic endurance) in 2013, 2014 and 2015. The results showed that hand grip strength (right and left), lower limb flexibility, and aerobic endurance exhibited good specificity and sensitivity. However, when the cut-off points were used to verify the risk of falls, only lower limb flexibility was associated with falls.

Identification of risk factors and predictors of falls in the female elderly population is important as the prevalence of falls in community-dwelling older woman ranges from $21 \%$ to $46 \%[17,18]$. This prevalence is $22.2 \%$ among older adults participating in physical activities and the recurrence of falls is 30\% among community-dwelling Latin American older adults $[9,11,18]$. Although we did not analyze the recurrence of falls, their prevalence decreased from 2014 (25\%) to 2016 (15\%). These findings support evidence that physical exercise is a useful approach to prevent falls in older women [13].

Elderly non-fallers scored better in the physical fitness components than fallers, a fact demonstrating the importance of creating strategies that reduce risk factors for falls [17]. Physical fitness is important and 
is linked to risk factors for falls since the loss of some physical functions due to aging or disease can predict how much the older adult is susceptible to falling [18].

The results of this study indicate low hand grip strength as a factor to identify older women at risk of falls within 2 years. A prospective cohort study involving older adults from Tasmania also found that hand grip strength and BMI can predict the risk of death from falls in older adults [19].

The present study shows that older women with poor lower limb flexibility are at a higher risk of falling than those with good lower limb flexibility. This finding agrees with the observation that there is a loss of flexibility with advancing age [12]. This loss is related to shortening of the hip flexors, which causes difficulties in daily activities and affects the gait pattern of older adults. Within this context, the components of physical fitness, including flexibility, influence stride length, which is the best indicator of gait variability in older adults [20].

In this study, only agility and aerobic endurance obtained in 2015 predicted falls, suggesting that these fitness components are associated with a more latent/ acute type of falls. These two tests measure the ability to walk faster (agility) and over a longer distance (resistance). These variables are influenced by other factors such as strength. In the case of older adults, the ability to walk declines because of the latency in muscle activation for postural adjustments, which decreases the ability to maintain postural balance [21, $22]$. This fact suggests that the declines in physical fitness components for the prediction of falls are interrelated, starting with strength and flexibility, followed by agility and aerobic endurance. Taken together, the findings show that exercise is an important factor for improving the physical fitness of older adults. A study [14] on Korean older adults with a history of falls submitted to a 12-week exercise program focusing on flexibility, balance, muscle strength and resistance showed improvement in functional capacity and in the fear of falling.

The findings of the present study suggest that falls can be predicted based on physical fitness variables, even in elderly exercise practitioners, since women who reported more falls exhibited poor performance in the hand grip strength, lower limb flexibility, agility, and aerobic endurance tests. Thus, physical exercises help reduce the gradual decline of physical fitness components, which can change life habits and daily routines of older adults [23]. Exercise programs are therefore important to improve or maintain physical fitness of the female elderly population, with fitness components being fundamental for predicting falls in older women $[9,10,13,24]$. In 2001, the American and British Geriatrics Societies [25] updated the guidelines for the prevention of falls in the elderly population. Among the items, numerous exercises can be useful to prevent falls, including balance, strength, flexibility, Tai Chi and cardiovascular resistance exercises and physical training carried out in individual and group sessions [26, 27].

This study has several strengths, including the follow-up of the sample for 4 years and the fact that the participants continued in the exercise program, which permitted to demonstrate a decrease in the long-term prevalence of falls. In addition, this study suggests cut-off points of some fitness components for this population. However, some limitations must be mentioned such as the self-report of falls, which may lead to underreporting by the older adults, as well as the lack of adjusting for other risk factors such as age, environmental factors and cognitive condition, which also interfere with falls. In addition, the fact that the sample was intentional implies that these findings cannot be extrapolated to other populations. On the other hand, the sample size was sufficient to reinforce the efficacy of the exercise program in improving and maintaining physical fitness to predict the risk of falls.

\section{Conclusion}

Poor performance in the lower limb flexibility, right and left hand grip strength, agility and aerobic endurance tests was associated with falls and these components are predictors of future falls in elderly exercise practitioners. Considering the relevance of this topic and its relationship with the aging process, additional studies that include other variables such as body composition and cognitive capacity are necessary to accurately predict the physical, biological and behavioral characteristics of the individual. We thus suggest that future studies use a larger sample size and compare the predictive ability of physical fitness components between older women practitioners of exercise and non-practitioners. In addition, it is necessary to determine the direct and indirect relationship between physical fitness components in the prediction of falls using structural equations. 


\section{Acknowledgements}

We thank the Programa de Extensão Grupo de Estudos da Terceira Idade (GETI) and Laboratório de Gerontologia (LAGER), Centro de Ciências da Saúde e do Esporte (CEFID), Universidade do Estado de Santa Catarina (UDESC); Conselho de Nacional de Desenvolvimento Tecnológico (CNPq), and Fundação de Amparo à Pesquisa e Inovação do Estado de Santa Catarina (FAPESC), Brazil. We also thank Centro de Investigação em Atividades Física e Saúde (CIAFEL), Portugal, for its support.

\section{References}

1. Miranda GMD, Mendes ACG, Silva ALA. Population aging in Brazil: current and future social challenges and consequences. Rev Bras Geriatr Gerontol. 2016;19(3):507-19.

2. Brasil. Ministério recomenda: é preciso envelhecer com saúde. Ministerio da Saúde; 2016.

3. Pinto EB, Nascimento C, Monteiro M, Castro M, Maso I, Campos A, et al. Proposal for a New Predictive Scale for Recurrent Risk of Fall in a Cohort of CommunityDwelling Patients with Stroke. J Stroke Cerebrovasc Dis. 2016;25(11):2619-26.

4. Carneiro JA, Cardoso RR, Duraes MS, Guedes MCA, Santos FL, Costa FMD, et al. Frailty in the elderly: prevalence and associated factors. Rev Bras Enferm. 2017;70(4):747-52.

5. Fernando E, Fraser M, Hendriksen J, Kim CH, MuirHunter SW. Risk Factors Associated with Falls in Older Adults with Dementia: A Systematic Review. Physiother Can. 2017;69(2):161-70.

6. Fabricio SCC, Rodrigues RAP, Costa Jr ML. Falls among older adults seen at a Sao Paulo State public hospital: causes and consequences. Rev Saude Publica. 2004;38(1):93-9.

7. Ding L, Yang F. Muscle weakness is related to slip-initiated falls among community-dwelling older adults. J Biomech. 2016;49(2):238-43.
8. Gianoudis J, Bailey CA, Ebeling PR, Nowson CA, Sanders $\mathrm{KM}, \mathrm{Hill} \mathrm{K}$, et al. Effects of a targeted multimodal exercise program incorporating high-speed power training on falls and fracture risk factors in older adults: a communitybased randomized controlled trial. J Bone Miner Res. 2014;29(1):182-91.

9. Bento PCB, Rodacki ALF, Homann D, Leite N. Exercícios físicos e redução de quedas em idosos: uma revisão sistemática. Rev Bras Cineantropom Desempenho Hum. 2010;12(6):471-9.

10. Toraman A, Yildirim NU. The falling risk and physical fitness in older people. Arch Gerontol Geriatr. 2010;51(2):222-6.

11. Streit IA, Mazo GZ, Virtuoso JF, Menezes EC, Gonçalves E. Aptidão física e ocorrência de quedas em idosos praticantes de exercícios físicos. Rev Bras Ativ Fis Saude. 2011;16(4):346-52.

12. Tomas MT, Galan-Mercant A, Carnero EA, Fernandes B. Functional Capacity and Levels of Physical Activity in Aging: A 3-Year Follow-up. Front Med (Lausanne). 2018;4:244.

13. Sherrington C, Tiedemann A, Fairhall N, Close JC, Lord SR. Exercise to prevent falls in older adults: an updated meta-analysis and best practice recommendations. N S W Public Health Bull. 2011;22(3-4):78-83.

14. Oh DH, ParkJE, Lee ES, Oh SW, Cho SI, Jang SN, etal. Intensive exercise reduces the fear of additional falls in elderly people: findings from the Korea falls prevention study. Korean J Intern Med. 2012;27(4):417-25.

15. Rikli R, Jones C. Development and validation of a functional fitness test for community residing older adults. J Aging Phys Act. 1999;7(2):129-61.

16. Jefferis BJ, Merom D, Sartini C, Wannamethee SG, Ash S, Lennon LT, et al. Physical activity and falls in older men: the critical role of mobility limitations. Med Sci Sports Exerc. 2015;47(10):2119-28.

17. Tanimoto Y, Watanabe M, Sun W, Sugiura Y, Hayashida I, Kusabiraki T, et al. Sarcopenia and falls in communitydwelling elderly subjects in Japan: Defining sarcopenia according to criteria of the European Working Group on Sarcopenia in Older People. Arch Gerontol Geriatr. 2014;59(2):295-9. 
18. Agudelo-Botero M, Giraldo-Rodriguez L, MurilloGonzalez JC, Mino-Leon D, Cruz-Arenas E. Factors associated with occasional and recurrent falls in Mexican community-dwelling older people. PLoS One. 2018;13(2):e0192926.

19. Balogun S, Winzenberg T, Wills K, Scott D, Jones G, Aitken $\mathrm{D}$, et al. Prospective associations of low muscle mass and function with 10-year falls risk, incident fracture and mortality in community-dwelling older adults. J Nutr Health Aging. 2017;21(7):843-8.

20. Ciprandi D, Zago M, Bertozzi F, Sforza C, Galvani C. Influence of energy cost and physical fitness on the preferred walking speed and gait variability in elderly women. J Electromyogr Kinesiol. 2018;43:1-6.

21. Lacroix A, Kressig RW, Muehlbauer T, Gschwind YJ, Pfenninger $B$, Bruegger 0 , et al. Effects of a supervised versus an unsupervised combined balance and strength training program on balance and muscle power in healthy older adults: a randomized controlled trial. Gerontology. 2016;62(3):275-88.
22. Claudino R, Santos MJ, Mazo GZ. Delayed Compensatory postural adjustments after lateral perturbations contribute to the reduced ability of older adults to control body balance. Motor Control. 2017;21(4):425-42.

23. Fidelis LT, Patrizzi LJ, Walsh IAP. Influência da prática de exercícios físicos sobre a flexibilidade, força muscular manual e mobilidade funcional em idosos. Rev Bras Geriatr Gerontol. 2013;16(1):109-16.

24. Kang L, Chen X, Han P, Ma Y, Jia L, Fu L, et al. A Screening tool using five risk factors was developed for fall-risk prediction in chinese community-dwelling elderly individuals. Rejuvenation Res. 2018;21(5).

25. Guideline for the Prevention of Falls in Older Persons. J Am Geriatr Soc. 2001;49(5):664-72.

26. Panel on Prevention of Falls in Older Persons AGS, Society BG. Summary of the Updated American Geriatrics Society/British Geriatrics Society Clinical Practice Guideline for Prevention of Falls in Older Persons. J Am Geriatr Soc. 2011;59(1):148-57.

27. Zhang X, Sun M, Liu S, Leung CH, Pang L, Popat UR, et al. Risk factors for falls in older patients with cancer. BMJ Support Palliat Care. 2018;8(1):34-7.

Received: 06/11/2018

Recebido: 11/06/2018

Approved: 06/21/2020

Aprovado: 21/06/2020 